\title{
"Dê-me Segurança ou the dou um Não": Em Busca do Eleitor Mediano no Referendo das Armas*
}

\author{
Ari Francisco de Araujo Junior ${ }^{\dagger}$, Fábio Augusto Reis Gomes ${ }^{\ddagger}$, Márcio \\ Antônio Salvato ${ }^{\S}$, Cláudio D. Shikida $₫$
}

Sumário: 1. Introdução; 2. A Economia Política dos Referendos; 3. Metodologia Econométrica e Resultados; 4. Conclusões; A. Tabelas.

Palavras-chave: Armas; Desarmamento; Referendo; Eleitor mediano.

Códigos JEL: K42; D72.

Em 2005, a sociedade brasileira participou de um referendo sobre o comércio legal de armas de fogo, e optou pela deste comércio. Nesse processo dois grupos de interesse foram formados, o grupo do SIM, favorável à proibição do comércio de armas de fogo, e o grupo do NÃO, em posição oposta. Assim, o objetivo deste artigo é analisar os argumentos de cada grupo, a partir de um modelo analítico e identificar os determinantes do resultado do referendo, utilizando dados em nível municipal. Os resultados indicam que a proporção de votos no NÃO é negativamente correlacionado com a taxa de homicídio em 2002 e positivamente correlacionado com a variação desta taxa de 1995 a 2002. Assim, nos municípios em que a recente da violência foi maior, os cidadãos não desejam abrir mão do direito de adquirirem armas de fogo.

On October 23, 2005, the Brazilian society faced a referendum with two options: "to not ban the legal market for firearms" and "to ban the legal market for firearms". Voters chose the first option. Along the months before the voting day, two interest groups were formed: one, called "No" - arguing for not banning the market - and the other group, called "Yes" - for the ban. This article

\footnotetext{
* Os autores são gratos aos pareceristas anônimos e a Cláudio Burian Wanderley por comentários muito construtivos. Qualquer erro é de responsabilidade dos autores.

${ }^{\dagger}$ Ibmec - Minas Gerais. E-mail: arifaj@ibmecmg.br

${ }^{\ddagger}$ Ibmec - São Paulo. Rua Quatá, 300, $4^{\circ}$ Andar, Sala 422, Vila Olímpia.São Paulo, SP, Brasil - CEP: 04546-042 Tel.: (11) $4504-2776$.

E-mail: FabioARG@isp.edu.br

$\S$ PUC - MG e Ibmec - Minas Gerais. E-mail: marcio.salvato@gmail .com

ף Ibmec - Minas Gerais. E-mail: claudiods@ ibmecmg . br
} 
has two main objectives: first, to analyze the arguments of each group using an analytical model and, two, to identify the determinants of the voter's choice using data at the local level. The main results indicate that the votes for No were negatively correlated to the homicide rate (measured in 2002) and positively correlated with the marginal change of the homicide rate (between 1995 and 2002. Thus, cities in which the violence increases more quickly, the citizens did not choose to ban the legal market for firearms.

\section{INTRODUÇÃO}

Em 2005, pela primeira vez, a sociedade brasileira participou de um referendo cuja proposta era a de proibir o comércio de armas de fogo no país. Como o Brasil é um país bastante violento, o referendo rapidamente ganhou maciço espaço na mídia e no cotidiano das pessoas. A fim de informar e influenciar a escolha dos eleitores, dois grupos foram formados: um a favor da proibição e outro contra.

O grupo do SIM - a favor da proibição - argumentou que a proibição da venda de armas de fogo poderia ter um efeito benéfico e considerável, principalmente, devido a três canais: $i$ ) redução de mortes por acidente com arma de fogo; ii) redução de crimes passionais; iii) redução do arsenal em mãos , haja visto que parte das armas ilegais é originalmente legal. Por outro lado, o grupo do NÃO - contra a proibição - argumentou que a proibição desarmaria o cidadão, não o criminoso. Além disso, sabendo que enfrentaria menor resistência, o criminoso teria maior incentivo para cometer crimes. Nesta perspectiva, a proibição levaria a um aumento da violência no país. Portanto, é fácil perceber que o referendo é uma questão de Economia Política, pois envolve uma escolha de política pública, grupos de interesse e, claro, um eleitor mediano.

O objetivo primeiro deste estudo é discutir a pertinência dos argumentos citados por cada grupo de interesse. Para tanto, foi construído um modelo analítico que procura formalizar os incentivos que afetam a decisão do eleitor pela manutenção ou não do comércio legal de armas de fogo. 0 principal resultado do modelo é que a posse de armas de fogo por uma parcela das vítimas potenciais pode inibir o criminoso, gerando uma externalidade positiva para as demais vítimas que não possuem arma de fogo.

Em segundo lugar, com o uso de dados em nível municipal, foi estimado um modelo econométrico para identificar os determinantes da vitória do NÃO no. Além de vários controles, considerou-se a taxa de homicídio em 2002, pois esta variável pode estar correlacionada com o custo da existência do mercado legal de armas, e a variação desta taxa entre 1995 e 2002, o que pode medir a percepção das potenciais vítimas sobre a escalada recente da violência. A fim de identificar o peso de cada município no resultado do referendo, foi utilizado como ponderador para cada município a proporção de eleitores que compareceram à votação, sendo obtidos os seguintes resultados: $i)$ na maioria dos Estados, quanto maior a taxa de homicídios, menor a proporção de votos no NÃO - um resultado esperado se for considerado que tal variável é uma proxy para o custo da existência do mercado legal de armas; ii) quanto maior a variação (aumento) da taxa de homicídios, maior a proporção de votos no NÃO - o que pode estar indicando que nas áreas nas quais a violência cresceu mais o eleitor não está disposto a abrir mão do efeito externalidade e confiar sua segurança exclusivamente ao Estado.

Além dessa introdução, na seção 2 , são descritas sucintamente as vantagens e desvantagens da Democracia Direta via referendo e analisadas as propostas dos grupos de interesse envolvidos por meio de um modelo analítico que estuda os incentivos econômicos envolvidos na escolha do eleitor. Na seção 3 estima-se o modelo econométrico para identificar os determinantes do resultado do referendo. A última seção apresenta as conclusões. 


\section{A ECONOMIA POLIITICA DOS REFERENDOS}

\subsection{Democracia Direta e Economia Política}

Qual o sentido econômico de um referendo? O referendo é uma das formas diretas de democracia, cujo estudo, em Teoria Econômica, é relativamente recente. ${ }^{1}$

A teoria econômica tradicional rejeita a democracia direta em prol da democracia representativa ${ }^{2}$ baseada no argumento clássico de Buchanan e Tullock (1962). Recentemente, contudo, este ponto de vista tem sido qualificado. Assim, por exemplo, Matsusaka argumenta que há evidências de que a democracia direta é superior à representativa. Em suas palavras:

"For one thing, representatives may not be fully accountable to their constituents (there may be agency problems, in modern jargon) and may choose policies that are harmful to many of them. There is now a great deal of theory and evidence suggesting the elected officials are less than perfect agents of the voters". [Matsusaka $(2005 \mathrm{~b}, 16)$ ]

Matsusaka (2005a,b) chama a atenção para duas mudanças que teriam diminuido os custos da adoção de métodos de democracia direta: ${ }^{3}$ as mudanças demográfica (aumento do nível educacional da população) e tecnológica (facilidade de acesso às informações graças à revolução digital).

Além disso, se a qualidade da informação é importante e está dispersa na sociedade, a democracia direta pode ser superior à democracia representativa. Neste sentido, pode-se pensar que o grau de dispersão é maior quando o conhecimento exigido para uma dada política é específico ${ }^{4}$ ou quando a política envolve questões morais, como o caso da eutanásia assistida ou o casamento de homossexuais. ${ }^{5}$ Obviamente, uma política pública pode envolver ambos os aspectos, como no caso do comércio de armas que pode ser visto tanto como um "direito à autodefesa" quanto um problema dependente da especificidade local (e.g., se alguns eleitores moram em locais mais sujeitos à violência do que outros).

Assim, o referendo brasileiro pode ser pensado como uma tentativa de se obter maiores informações sobre as preferências dos eleitores acerca do comércio de armas. Portanto, entender os determinantes da vitória do NÃO é um caminho indireto de se conhecer o eleitor mediano envolvido no debate sobre o comércio de armas.

\subsection{Os Grupos de Interesse no referendo}

Como a sociedade se organizou em torno dessa discussão? De forma bem simples, os grupos de interesse se posicionaram em torno das seguintes opções: proibir o comércio de armas no país (identificado como SIM) e não proibir o comércio de armas no país (identificado como NÃO). Do lado do SIM, a mais visível representante foi a Organização Não-Governamental "Viva Rio". Quanto ao NÃO, formou-se uma frente parlamentar "Voto Não". Um resumo dos principais argumentos de ambos encontram-se na Tabela 1.

Da tabelas 1 é fácil ver que alguns argumentos não se aplicam. Por exemplo, do lado do SIM, é fato que "armas de fogo" são perigosas, mas assim também o são facas, martelos ou mesmo garrafas.

\footnotetext{
${ }^{1}$ Ver Matsusaka (2005b,a) para um bom resumo do tema. Vale ressaltar que, como destaca o autor, a democracia direta tem sido uma forma de instituição adotada cada vez mais nos EUA para fins de políticas públicas. As consequências econômicas desta tendência são analisados na bibliografia citada.

2 Ver Buchanan e Tullock (1962).

${ }^{3}$ Dos quais o referendo é um dos métodos.

${ }^{4}$ Matsusaka cita o exemplo de regulações de segurança ocupacional, que exigem o conhecimento de situações específicas de locais de trabalho.

${ }^{5}$ Vale a pena citar o autor: "For example, Matsusaka (1992) shows that initiatives are more likely to address broad distributional and moral issues while technical regulatory and government administration issues are left to the legislature". [Matsusaka (2005b, 23)]
} 
Além disso, claro, o argumento é tal que nem mesmo policiais deveriam portar armas. Do lado do NÃO, por sua vez, o argumento da "dominação estrangeira" do mercado doméstico provavelmente não se sustenta, a não ser que a redução do mercado interno inviabilize a produção das empresas nacionais devido às deseconomias de escala. ${ }^{6}$

Tabela 1 - Os Argumentos dos Grupos de Interesse

\begin{tabular}{|c|c|}
\hline SIM & NÃO \\
\hline $\begin{array}{l}\text { - Armas têm como finalidade a } \\
\text { "morte". Logo, serão sempre } \\
\text { perigosas. } \\
\text { - O cidadão não estaria desprote- } \\
\text { gido já que o Estatuto prevê que re- } \\
\text { sponsáveis pela segurança pública } \\
\text { ou privada poderiam portar armas } \\
\text { (além de outras exceções). } \\
\text { - Parte significativa das armas ile- } \\
\text { gais eram, originalmente, legais. } \\
\text { - Dado o fator surpresa presente } \\
\text { em ações criminosas, a posse de } \\
\text { arma pelo cidadão honesto não se- } \\
\text { ria condição suficiente para lhe pro- } \\
\text { teger. } \\
\text { - O fim do comércio implicaria em } \\
\text { diminuição dos crimes passionais } \\
\text { e mortes acidentais envolvendo ar- } \\
\text { mas de fogo. }\end{array}$ & $\begin{array}{l}\text { - O governo deveria combater o } \\
\text { comércio ilegal de armas. } \\
\text { - A posse de arma, em si, diminui } \\
\text { o risco de assaltos individualmente } \\
\text { (o criminoso não gostaria de entrar } \\
\text { em um conflito armado com a ví- } \\
\text { tima) e coletivamente (ao não ter } \\
\text { certeza sobre a existência de armas } \\
\text { por parte das vítimas, desestimula- } \\
\text { se o crime contra o patrimônio). } \\
\text { - O fim do comércio significaria a in- } \\
\text { vasão do mercado doméstico de ar- } \\
\text { mas por firmas estrangeiras. } \\
\text { - o Estado deveria fornecer segu- } \\
\text { rança e/ou políticas de Segurança } \\
\text { pública antes de propor o desarma- } \\
\text { mento (e deveria se preocupar em } \\
\text { controlar o contrabando de armas } \\
\text { em regiões fronteiriças). }\end{array}$ \\
\hline
\end{tabular}

Fonte: Adaptado de Referendo (2005) e Revista Consultor Jurídico (2005).

Após o resultado do referendo, alguns - que argumentaram pela defesa do mesmo por se tratar de uma consulta popular - acusaram os defensores do NÃO de terem influenciado os eleitores. Entretanto, nem sempre a competição de grupos de interesse "distorce" a opinião do eleitor mediano, conforme destaca Wittman (1999) em um exemplo bastante similar ao caso em estudo, o da NRA (National Rifle Association, ANR em português):

"A ANR é provavelmente o grupo de pressão mais comumente citado pelos que acreditam que o Congresso é controlado por interesses especiais, em detrimento da maioria. Um argumento padrão é que esta organização deturpa a vontade da maioria por meio de lobby no Congresso. Todavia, é ingênuo culpar o Congresso dessa forma, quando nos plebiscitos o controle de armas também não passa. Por exemplo, em 1982, 63\% dos eleitores da Califórnia votaram contra o controle de armas leves, e apenas $37 \%$ votaram a favor. Portanto, a imobilidade do Congresso sobre o controle de armas pode refletir a vontada da maioria, em vez do resultado dos lobbies da Associação Nacional do Rifle”. [Wittman (1999, p.139)]

Segundo Referendo (2005), enquanto as empresas domésticas de armas e munições foram os grandes financiadores do NÃO (Taurus e CBC, em um total de R\$ 5 milhões), o SIM recebeu contribuições mais

\footnotetext{
${ }^{6}$ De fato, o argumento é compatível com a ajuda financeira que a Frente Parlamentar "Voto Não" recebeu de empresas nacionais (Taurus e $\mathrm{CBC}$ ). Porém, uma interpretação possível é que tais empresas estavam mais preocupadas em manter o tamanho do mercado, do que com uma suposta "dominação estrangeira".
} 
dispersas (Ambev, CBF e Prestadora de Serviços Estruturar, por exemplo, em um total de R\$ 2,4 ). ${ }^{7}$ Assim, enquanto o lado da oferta de armas de fogo se uniu no financiamento do NÃO, o SIM não teve uma alta representatividade de eleitores dispersos, tendo sido representado por grupos bastante heterogêneos entre si. $^{8}$

Feita esta breve digressão acerca do referendo e dos grupos de interesse envolvidos, percebe-se que nem sempre os argumentos utilizados por ambos seguem alguma lógica econômica para fins de análises de custo-benefício. Os argumentos que nos permitem fazer tais análises serão discutidos na seção seguinte.

\subsection{Analisando os Argumentos dos Grupos de Interesse ${ }^{9}$}

Os argumentos apresentados na seção anterior podem ser discutidos através de um arcabouço teórico simples. O grupo do SIM defendia que, no Brasil, o número de crimes passionais e mortes acidentais é muito elevado e, mais importante, grande parte das armas utilizadas pelos criminosos são armas compradas legalmente que foram roubadas. Para o grupo do NÃO a proibição desarmaria apenas o cidadão honesto e se o criminoso tomar conhecimento de que as vítimas em potencial estão desarmadas, o número de crimes aumentaria.

Quanto à ocorrência de crimes passionais $(P)$ e mortes por acidente $(A)$, em princípio, a venda de armas aumenta a chance de ocorrência de ambos, havendo um custo para a sociedade $c(P, A)$ tal que $c_{i}(P, A)>0$ para $i=P, A$. No caso de crimes passionais, o argumento procede apenas na suposição de que armas de fogo não possuem um substituto perfeito. Se, na ausência de armas de fogo, armas brancas são usadas, por exemplo, então o número de crimes passionais não se reduziria com a proibição do comércio de armas de fogo. Porém, como a substituição não deve ser perfeita, mantemos a função custo $c(P, A)$. Por outro lado, o argumento de que as armas legais são transformadas em arsenal nas mãos de criminosos não é tão simples. Suponha que os criminosos possam adquirir armas de diversas formas - como ocorre de fato - e que $X \%$ destas armas ilegais são, originalmente, legais. Mesmo com a proibição do comércio de armas, não é óbvio que o número de armas com os criminosos vai se reduzir em $X \%$, mesmo no longo prazo após a depreciação destas armas, pois os criminosos poderiam recorrer a outras fontes. De todo modo, defina $g(q)$ como o custo gerado pela proporção de armas legais apropriada pelos criminosos, em que $q$ é a proporção de vitimas que possui armas de fogo, de modo que $g^{\prime}(q)>0$.

Para analisar o argumento daqueles que são contra a proibição do comércio vamos considerar o seguinte modelo. A população é composta por vítimas potenciais e criminosos. Seja $w_{i}$ a renda da vítima $i$ e $\delta_{j}$ a fração desta renda que é apropriada pelo criminoso $j$. O parâmetro $\delta_{j}$ pode ser visto como a habilidade do criminoso ou o tipo de crime que ele comete. Assim, o retorno do crime é $\delta_{j} w_{i}$. Seja $F$ o custo do crime em caso de insucesso, isto é, a pena do crime, levando em conta todos os custos

\footnotetext{
${ }^{7}$ Entretanto, é bom lembrar que o Viva Rio, talvez a principal defensora do SIM recebe recursos da Fundação Ford, da Fundação Soros e ONU, dentre outras.

${ }^{8}$ É possível que esta heterogeneidade seja causada pelo alto custo de transação político inerente à organização de grandes grupos.

${ }^{9}$ Nos EUA há uma vasta literatura - inconclusiva, é bom destacar - sobre a eficácia do porte de armas no combate à violência (ver, por exemplo, Harrison et alii (2000), Kovandzic e Marvell (2002), Helland e Tabarrok (2004), Lott (2004), Lott et alii (2002), Ayres e Donohue III (2003), Donohue e Levitt (2001), Plassmann e Lott (2002), Lott (1999), Lott e Landes (2000)). Em algumas ocasiões o debate ultrapassou o limite da ética acadêmica. Por exemplo, Michael Bellesiles, professor de história emérito da Emory University e crítico do direito ao porte de armas, perdeu seu emprego em 2002, após a comprovação - por um comitê acadêmico - de que seria culpado pela fabricação de dados em seu livro The Origins of a National Gun Culture. Não muito tempo depois, em 2003, John R. Lott Jr., economista favorável ao porte de armas e autor do polêmico More Guns, Less Crime, sofreu críticas similares. Para detalhes sobre os dois escândalos, ver De La Merced (2002) e Noah (2003). Ademais, não discutiremos essa literatura pois, em geral, ela avalia se mudanças na legislação afetam o padrão de criminalidade e neste trabalho, com a manutenção do comércio de armas, podemos avaliar apenas a percepção dos eleitores sobre o assunto. Para os interessados no tema, uma revisão recente é a de Kwon e Baack (2005).
} 
de oportunidade envolvidos, somados aos custos morais. Seja $p(\bullet)$ a probabilidade de insucesso do crime e, por conseguinte, $1-p(\bullet)$ a probabilidade de sucesso do mesmo. Consideramos que $p=p\left(I_{a}\right)$ em que $I_{a}$ é uma função indicadora que é igual a um se a vítima possui uma arma de fogo e zero caso contrário. Supomos que a probabilidade de insucesso é maior se a vítima possui uma arma de fogo, isto é, $p(1)=\lambda p(0)$, em que $\lambda>1$.

Considere um criminoso que está diante da decisão binária de cometer ou não um crime. Suas preferências são representadas pela função utilidade $u(\bullet)$, do tipo von Neumann-Morgenstern. Como usual $u^{\prime}(\bullet)>0$ e $u^{\prime \prime}(\bullet)<0$. Supõe-se que o criminoso não consegue identificar quais vítimas estão armadas, mas consegue identificar a proporção de vítimas em potencial que possuem arma de fogo $(q)$. Então, a utilidade esperada do criminoso $j$ ao atacar a vítima $i$ é dada por:

$$
E[u(C(j, i))]=q u\left([1-p(1)] \delta_{j} w_{i}-p(1) F\right)+(1-q) u\left([1-p(0)] \delta_{j} w_{i}-p(0) F\right)
$$

Seja $v_{0}$ o valor de reserva do criminoso - o retorno que ele obteria no mercado de trabalho. Então o crime é cometido quando $E[u(C(j, i))]>E\left[u\left(v_{0}\right)\right]$.

Proposição 2.1. À medida em que a proporção de pessoas armadas na sociedade aumenta, menores são as chances de um indivíduo cometer um ato criminoso.

Demonstração. Basta mostrar que o efeito de $q$ sobre $E[u(C(j, i))]$ é negativo, pois supõe-se que $v_{0}$ não depende de $q$. A prova segue de $u^{\prime}(\bullet)>0$ e $\lambda>1$.

Portanto, quanto maior a proporção de vítimas em potencial armada, menor o benefício da ação criminosa e maior a chance do criminoso desistir de cometer o ilícito. ${ }^{10}$

Proposição 2.2. À medida em que mais indivíduos portam armas de fogo, a probabilidade de qualquer indivíduo ser atacado diminui ou permanece a mesma.

Demonstração. Suponha que $\delta_{j}$, wr e $q$ são tais que $E[u(C(j, r))]<E\left[u\left(v_{0}\right)\right]$. Então, fixando $q$, todos os indivíduos com renda igual ou inferior a $w r$ não serão atacados pelo criminoso $j$, independentemente de tais vítimas em potencial possuírem ou não arma de fogo, pois $E[u(C(j, r))]$ diminui quando a renda cai. Quando $q$ aumenta, pela proposição 1, este efeito se intensifica e existirá uma renda $w_{t}>w_{r}$ abaixo da qual as pessoas não serão atacadas. Porém, para valores de renda mais altos, a chance de um indivíduo ser atacado não se altera.

A proposição anterior nos diz que pessoas que não possuem uma arma de fogo são beneficiadas por aquelas que adquirem tais armas, o que caracteriza uma externalidade positiva, $h(q)$, tal que $h^{\prime}(q)>0$. Neste contexto, o argumento do grupo do NÃO procede.

Neste arcabouço, o comércio de armas é benéfico quando $h(q)>c(P, A)+g(q) .{ }^{11}$ Se a capacidade de reposição de armas dos criminosos é reduzida na ausência do comércio legalizado, então $g(\bullet)>0$. Porém, se os criminosos podem recorrer a outras fontes para se armarem sem qualquer perda, $g(\bullet)=0$. Em outras palavras, este termo tem pouca importância para a discussão, pois seria substituído por outra fonte, como o contrabando.

Assim, caso a percepção da população seja que a proibição da venda de armas não desarmaria o criminoso, $g(\bullet)=0$, e que a externalidade positiva seja suficientemente grande, a ponto de superar o custo dos crimes passionais e mortes por acidente, $h(q)>c(P, A)$, então o resultado esperado do

\footnotetext{
${ }^{10}$ Supomos que $q$ não afeta $E\left[u\left(v_{0}\right)\right]$. Mesmo que $q$ reduza $E\left[u\left(v_{0}\right)\right]$, se isso ocorrer em magnitude inferior ao impacto sobre $E[u(C(i, j))]$, o resultado permanece.

${ }^{11}$ Há ainda um benefício que omitimos, pois ele não foi mencionado na mídia. O comércio de armas, assim como qualquer troca, ocorre apenas se é mutuamente vantajoso para comprador e vendedor e, portanto, gera um excedente para a sociedade, que depende positivamente do tamanho deste mercado.
} 
referendo seria a não-proibição da venda de armas de fogo. ${ }^{12}$ De fato, usando o princípio da preferência revelada podemos concluir que, ao menos do ponto de vista da sociedade, $h(q)>c(P, A)+g(q)$, isto é, o benefício do comércio legal de armas de fogo é superior ao seu custo. ${ }^{13}$

Para sumarizar: i) mesmo que parte significativa das armas ilegais sejam, originalmente, legais, isso não é o bastante para concluirmos que a proibição do comércio desarmaria o criminoso, pois os criminosos poderiam recorrer a outras fontes de armamento; ii) o que gera a externalidade positiva, discutida acima, é o fato de os criminosos não possuírem o monopólio das armas de fogo. Note que, não é necessário que o cidadão use efetivamente a arma em seu porte, basta apenas que o criminoso não saiba quem não possui arma de fogo. Portanto, como levantado pelo grupo do NÃO "a existência de armas por parte das vítimas, desestimula o crime". Isto invalida também o argumento de que "a posse de arma pelo cidadão honesto não seria condição suficiente para the proteger". Mesmo que isso pudesse ocorrer em alguns casos, como crimes deixam de ocorrer devido à externalidade, este argumento não pode ser generalizado; iii) segundo o grupo do SIM "O cidadão não estaria desprotegido já que o Estatuto prevê que responsáveis pela segurança pública ou privada poderiam portar armas", porém este argumento seria válido apenas se a população confiasse no monopólio da coerção pelo Estado.

Por fim, uma última ressalva é necessária. Poder-se-ia argumentar que a medida que $q$ aumenta, nos casos nos quais permanece a desigualdade $E[u(C(j, r))]>E\left[u\left(v_{0}\right)\right]$, o criminoso agiria com maior violência. Ou seja, à medida que mais pessoas possuíssem armas de fogo o número de crimes diminuiria, porém sabendo do maior potencial de defesa da vítima, o criminoso agiria com maior agressividade. Neste caso, o argumento do grupo do NÃO poderia ser contestado dependendo de qual é a métrica usada para se medir à violência.

Na discussão acima são identificadas algumas variáveis-chave como $q, P$ e $A$. Porém, como estas não estão disponíveis, não é possível testar algumas das predições acima a partir de um modelo econométrico estrutural. No entanto, é possível implementar um tipo de forma reduzida deste, ao investigar quais são os determinantes do voto do eleitor. Nesta perspectiva, seria analisada a percepção da população de cada município em relação à diferença $h(q)-[c(P, A)+g(q)]$ por meio de variáveis como renda, educação, taxa de homicídio e etc.

\section{METODOLOGIA ECONOMÉTRICA E RESULTADOS}

\subsection{Modelo Econométrico}

O objetivo do exercício econométrico é analisar o impacto das taxas de crime e sua variação recente, além de outros fatores, sobre a proporção de votos contrários à proibição da venda de armas de fogo nos municípios brasileiros, a partir do resultado do Referendo de 2005. Apesar da vitória maciça do NÃO, a variabilidade observada em seus votos entre os municípios permite que se explore quais foram os fatores que levaram a rejeição da proibição da venda de armas de fogo.

O modelo de regressão linear a ser estimado, então, por mínimos quadrados ordinários é: ${ }^{14}$

$$
N \tilde{A} O_{i}=\alpha+X_{i} \beta+\delta_{0} \text { homicidios }_{i}+\delta_{1} \text { var.homicidios }_{i}+\varepsilon_{i}
$$

em que $i=1, \ldots, n$ são municípios; $N A O_{i}$ é o logaritmo natural da proporção de votos contrários à proibição da venda de armas no município $i$; $X_{i}$ são variáveis de controles; homicidios $_{i}$ é o logaritmo

\footnotetext{
12 No Brasil, em 2003, segundo dados da ONG Criança Segura, acidentes com armas responderam por apenas $1 \%$ das mortes acidentais de crianças enquanto os afogamentos responderam por $25 \%$ das mortes acidentais de crianças. Assim como nos Estados Unidos, há maior chance de uma criança morrer afogada em uma piscina do que de um acidente com uma arma.

${ }^{13}$ Como, em geral, a proporção de vítimas potenciais é suficientemente superior a proporção de criminosos na sociedade, analisar o interesse da vítima pode gerar uma aproximação bastante razoável do resultado do referendo.

${ }^{14}$ Por causa do possível problema de heterocedasticidade utilizamos o estimador robusto de White (1980).
} 
taxa de homicídios para cada 100 mil habitantes do município $i$ em 2002 (informação mais recente); var.homicidios é a variação de homicidios entre 1995 e 2002; $\alpha, \beta, \delta_{0}$ e $\delta_{1}$ são os parâmetros a serem estimados e $\epsilon_{i}$ é o erro aleatório.

Segundo o modelo descrito na seção anterior, quanto maior $h(q)$ e menores $g(\bullet), P$ e $A$, maior tende a ser a proporção de votos contrários à proibição (NÃO). Consideramos que var.homicidios é uma proxy para a percepção dos agentes acerca de sua segurança. A idéia é que uma escalada rápida da violência pode ter um efeito mais significativo do que um nível elevado e constante ao longo do tempo, pois neste caso haveria um efeito acomodação. De fato, segundo Rabin (1998), a evidência da psicologia sugere que as pessoas se preocupam mais com níveis relativos do que absolutos de sua cesta de consumo. Portanto, num contexto de violência crescente, muito provavelmente os eleitores não estariam dispostos a abrir mão da externalidade propiciada pela posse privada de armas de fogo, isto é, $h(q)$ é elevado. Por outro lado, como proxy para $g(\bullet), P$ e $A$ utiliza-se a variável homicidio. Assim, espera-se uma correlação negativa entre homicidios e a variável dependente.

As variáveis de controle são apresentadas abaixo e permitem que se aprofunde a investigação sobre quais seriam os determinantes, em nível municipal, dos resultados do referendo.

A variável dependente $(n a o)$ do exercício proposto tem como fonte o Tribunal Superior Eleitoral (TSE). Como pode ser observado na Tabela 2 , a proporção de votos contrários à proibição da venda de armas de fogo ultrapassou os $69 \%$ (desvio-padrão de 12,9). A menor proporção de votos contrários à proposta do referendo foi observada no município de Palmeiras, na Bahia, enquanto a maior proporção ocorreu em Jordão, no estado do Acre.

As variáveis homicidios e var.homicidios são provenientes do Sistema de Informações sobre Mortalidade do Ministério da Saúde. No entanto, as mesmas não estão disponíveis para todos os municípios do Brasil (estão apenas disponíveis para 1831 municípios). Esse fato gera uma dúvida: será que existe algum viés de seleção dos municípios em nossa amostra? Em outras palavras, será que a amostra de 1831 municípios é representativa da população de 5564 municípios brasileiros? A Figura 1 apresenta as distribuições ${ }^{15}$ da proporção de votos no NÃO para a população e para a amostra que será utilizada nas regressões. Os resultados sugerem que o problema de viés de seleção não foi relevante na definição da amostra. Isso parece ser confirmado pela comparação das principais estatísticas descritivas das referidas distribuições (Tabela 2). ${ }^{16}$ Com exceção do valor mínimo, as duas amostras apresentam estatísticas muito semelhantes.

Tabela 2 - Estatísticas Descritivas da Variável Dependente

\begin{tabular}{|c|c|c|c|c|c|}
\hline \multicolumn{7}{|c|}{ Variável: Proporção de votos no NÃO } \\
\hline Amostra & $\mathrm{N}^{0}$ observações & Média & Desv.Padrão & Mínimo & Máximo \\
\hline Completa & 5564 & 68,70 & 12,85 & 21,40 & 97,44 \\
\hline Analisada & 1831 & 68,33 & 12,94 & 27,28 & 96,93 \\
\hline
\end{tabular}

As variáveis de controle municipais são:

Domicílios logaritmo da proporção de domicílios pagos/quitados como proxy para ativos reais;

Educação logaritmo da proporção de pessoas com até 4 anos de estudo no grupo etário dos 18 a 24 anos;

Renda renda familiar per capita;

\footnotetext{
${ }^{15}$ Para estimar as densidades, utilizamos o estimador de núcleo de Epanechnikov.

${ }^{16}$ A Tabela 3 reforça a representatividade da amostra no nível estadual.
} 
Figura 1 - Distribuição da variável dependente amostra completa (a) e amostra analisada (b)

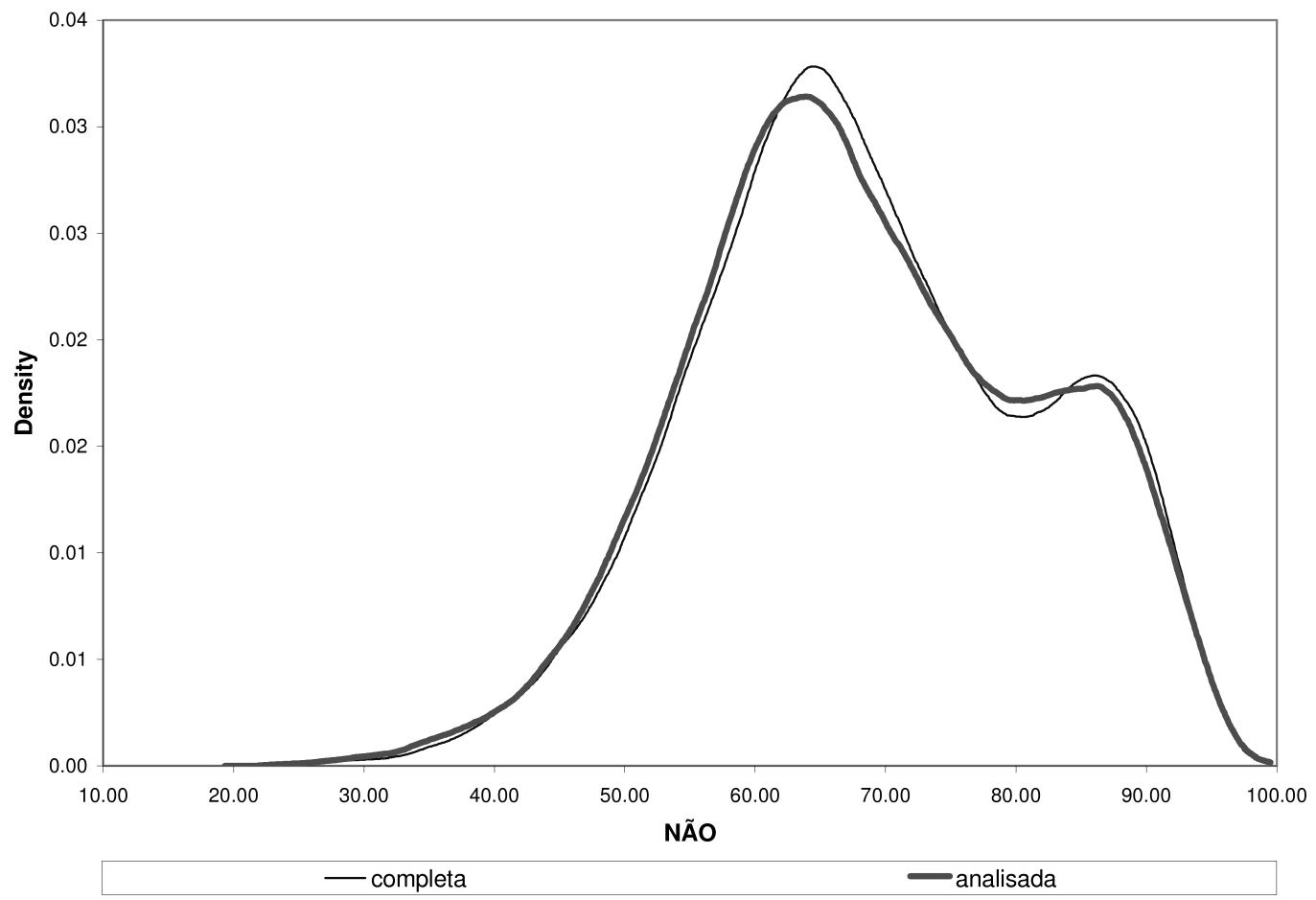

Pobreza logaritmo da proporção de pobres, isto é, indivíduos com renda domiciliar per capita inferior a R\$ 75,50 - 0,5 salário mínimo de 2000 -, como proxy de fluxo de renda;

Theil logaritmo do Theil da distribuição de rendimentos, como medida da desigualdade nos rendimentos;

Densidade logaritmo da densidade demográfica;

Rural logaritmo da proporção da população residente em área rural.

Todas estas variáveis referem-se ao ano de 2000 e foram obtidas do Atlas do Desenvolvimento Humano (2003), cuja fonte primária é o Censo Demográfico do IBGE de 2000. As estatísticas descritivas e correlações podem ser encontradas na Tabela 4. São incluídas como proxies de riqueza/renda as variáveis domicilios, renda e pobreza, e como proxy de capital humano a variável educação, pois se os benefícios do comércio de armas superam os custos, esta diferença deve se intensificar em regiões mais ricas - nas quais as vítimas em potencial têm mais a perder. A variável rural é incluída pois eventualmente tais regiões podem estar menos protegidas pelo Estado e seus moradores podem ter uma percepção diferenciada acerca do tema. Segundo o argumento do grupo do NÃO, residentes em zonas rurais tenderiam a votar pela manutenção do comércio de armas. Portanto, espera-se que o sinal deste coeficiente seja positivo. A variável Theil é incluída como uma medida de dispersão da renda, porque supõe-se que um aumento da distância entre ricos e pobres pode gerar tanto um aumento na demanda pela proteção estatal quanto um aumento na demanda por armas. Neste caso, o sinal esperado é ambíguo. A variável 
densidade captura o efeito do aumento da probabilidade de encontros entre criminosos e vítimas na cidade. Como no caso anterior, o efeito esperado é ambíguo.

Por fim, consideramos dummies por estados, pois não necessariamente as variáveis consideradas captaram toda a heterogeneidade das unidades da federação ${ }^{17}$.

No modelo descrito acima todos os municípios apresentam o mesmo peso, porém os mesmos possuem números distintos de eleitores e para se fazer qualquer análise sobre o resultado do referendo é preciso levar isto em conta. Então, o modelo é reestimado usando como ponderador o peso eleitoral que cada município teve no referendo. Ou seja, considera-se que o resultado de cada município representa uma parcela do resultado do Brasil como um todo. Esta parcela é igual ao número de pessoas que compareceu para votar em cada município em relação ao total de comparecimentos no Brasil inteiro.

\subsection{Resultados}

Os resultados do modelo econométrico são apresentados nas Tabelas 5 e 6 . Na primeira tabela são reportadas as regressões para nível municipal e na segunda tabela é feita a ponderação pelo peso eleitoral de cada município.

No que se refere à Tabela 5 , primeiramente foram consideradas todas as variáveis explicativas como reportado na primeira coluna (Modelo I), porém encontrou-se evidência de multicolinearidade severa entre as variáveis educacao, renda e pobreza e optou-se pela manutenção da primeira em detrimento das demais (Modelo II) ${ }^{18}$. Em seguida, foi testada a importância dos efeitos regionais através da inclusão, primeiramente, de um vetor composto de dummies de nível (Modelo III) ${ }^{19}$ e de um vetor composto destas e também de dummies de inclinação para a variável homicidios (Modelo IV). A significância do vetor completo de dummies na regressão IV sugere que as regressões anteriores omitiram variáveis relevantes. Em resumo, o principal resultado é aquele exposto na última coluna da Tabela 5. De qualquer forma, vale a pena comentar os resultados de todas as regressões da Tabela 5.

Após a verificação da multicolinearidade no modelo I, optou-se conforme mencionado, pela manutenção da educacao e exclusão de renda e pobreza, resultando no modelo II. Destas duas primeiras colunas observa-se que as variáveis estatisticamente significativas são homicidios, domicilios, educacao, e densidade, a 5\% de significância. Contrário ao esperado, a variável homicidios apresenta sinal positivo e a var.homicidios não foi significativa, nos dois modelos. Observa-se também alguma variação na significância estatística de alguns coeficientes: homicidios passa de 5 para $1 \%$ e a desigualdade deixa de ser significativa.

No próximo par de modelos, III e IV, foram acrescentadas as dummies de estados. Apenas o último modelo apresentou variáveis estatisticamente significativas (homicidios e var.homicidios), além dos vetores de dummies de nível e de inclinação.

Qualitativamente, os resultados sugerem que, tudo o mais mantido constante, em regiões mais violentas, menor foi a proporção de votos contrários à proibição da venda de armas. Apesar disso, nos municípios em que a variação da violência foi importante, maior foi a proporção de votos contrários à proibição. Observa-se também que a proporção de votos NÃO tem relação positiva com Rural.

Na Tabela 6, as regressões da Tabela 5 foram replicadas, agora considerando o peso dos eleitores na amostra (Modelos V - VIII). O resultado imediato é um ganho na significância estatística em praticamente todos os coeficientes estimados (todas as variáveis são significativas ao nível de $1 \%$ em todas as especificações). Tal como anteriormente, os modelos V e VI correspondem às estimativas incluindo todas as variáveis e a mitigação do problema de multicolinearidade entre renda, educacao e pobreza.

\footnotetext{
${ }^{17}$ Referimo-nos a estas como dummies regionais ou estaduais indistintamente exceto em menção contrária.

${ }^{18}$ Utilizamos o variance inflation factor para identificar o problema de multicolinearidade e para escolher a variável educação em detrimento das duas outras, minimizando o VIF. Ver tabelas 7 a 10.

${ }^{19}$ Vale lembrar que o coeficiente da taxa de homicídios corresponde agora ao efeito desta variável sobre a proporção de votos contrários à proibição da venda de armas no Distrito Federal.
} 
Assim, por exemplo, o modelo VI, no qual o problema de multicolinearidade é minorado, tem-se que, cada aumento de $10 \%$ em homicidios, reduz a proporção de votos contrários à proibição da venda de armas em $0,045 \%$. Com exceção de domicilios, todas as outras variáveis possuem impacto negativo sobre a proporção de votos contrários à proibição. Como esperado, se a externalidade é importante, em áreas mais ricas, os indivíduos tendem a não abrir mão da possibilidade de possuir uma arma de fogo.

Tal como na Tabela 5, as duas últimas colunas - modelos VII e VIII - consideram peculiaridades regionais. Tomando-se o modelo VIII como benchmark, os efeitos da variável homicidios sobre cada estado são apresentados na Figura $2 .^{20}$ Nota-se que o efeito negativo de homicidios continua válido para a maioria dos estados e que, apenas em nove deles, o efeito de homicidios é positivo. Ou seja, em estados como Pernambuco, Rio de Janeiro, Rio Grande do Sul e outros, quanto mais violenta a região, maior foi a proporção de votos contrários à proibição da venda de armas. Tal como esperado, nos modelos IV e VIII, o efeito de var.homicidios é positivo. ${ }^{21}$

As variáveis riqueza, educacao e desigualdade estão positivamente relacionadas à proporção de votos contrários à proibição da venda de armas. Cada aumento de $10 \%$ em riqueza, educacao e desigualdade gera, respectivamente, um aumento de $0,08,0,239$ e $0,182 \%$ sobre a proporção de votos contrários à proibição da venda de $\operatorname{armas}^{22}$.

Figura 2 - Efeitos das taxas de homicídios sobre a proporção de votos no NÃO

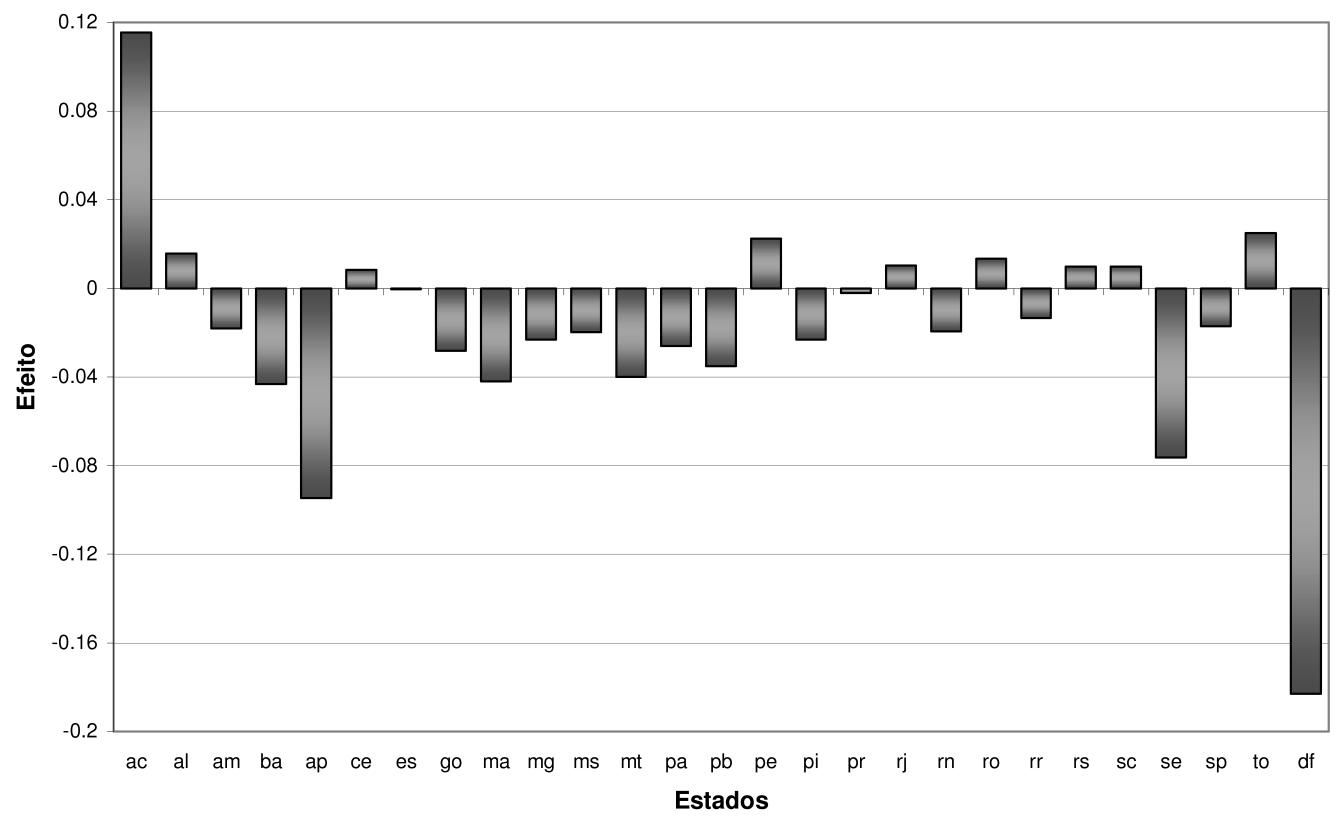

${ }^{20}$ Na Figura 2, os valores já correspondem ao efeito particular de cada estado, isto é, para cada estado soma-se o coeficiente de homicídios com o coeficiente da interação entre homicídios e a dummy do respectivo estado.

${ }^{21}$ É bom lembrar que outra diferença entre as regressões IV (municipal) e VIII (eleitor mediano) consiste no fato de que apenas nesta última todas as variáveis são estatisticamente significativas a $1 \%$.

22 Isto parece indicar que, para as potenciais vítimas, a segurança pública e a segurança privadas são, ambas, bens normais. Na inexistência de barreiras à compra de armas de fogo, aumentos de renda do eleitor mediano aumentam a demanda de ambos. 
Além disso, quanto maior a densidade, menor a proporção estimada de votos para o NÃO no referendo. Supondo que, em grandes cidades, os incentivos à prática criminosa (com ou sem o uso de armas de fogo) são maiores ${ }^{23}$, a opção pela proibição do comércio de armas de fogo pode ser uma tentativa da sociedade de aumentar os custos da ação criminosa.

Finalmente, ao contrário do que possivelmente esperavam os defensores do NÃO, quanto maior a população rural de certa região - captada pela variável Rural - menor a proporção de votos contrários à proibição da venda de $\operatorname{armas}^{24}$. Quantitativamente, a cada aumento de $10 \%$ em densidade e Rural, a proporção de votos contrários à proibição da venda de armas reduz-se em 0,032\% e 0,098\%, respectivamente.

Conforme discutido, a variável homicídios atuaria como uma proxy para o custo do comércio de armas e a sua variação mediria a percepção do eleitor sobre a evolução da violência e, como esperado, a primeira apresentou sinal negativo na maioria dos Estados enquanto a segunda apresentou sinal positivo. As variáveis que medem a riqueza (domicílios pagos/quitados) e o capital humano (educação) também apresentaram sinal positivo e, portanto, tudo mais constante, as regiões mais ricas preferem não confiar sua segurança unicamente ao Estado. Por fim, ressalta-se que, ao contrário do esperado, a variável rural apresentou sinal negativo, ainda que próximo de zero.

\section{CONCLUSÕES}

O objetivo do artigo foi analisar o resultado do Referendo sobre a proibição do comércio de armas de fogo, em 2005. Para tanto, os argumentos dos grupos de interesse envolvidos na disputa foram analisados por meio de um modelo econômico e, em seguida, foram estimadas diversas especificações econométricas, com e sem ponderação, para dados municipais.

O modelo econômico proposto é caracterizado por heterogeneidade de agentes (vítimas e criminosos) para formalizar os incentivos que afetam a decisão do eleitor pela manutenção ou não do comércio legal de armas de fogo. A principal conclusão, é que a posse de armas de fogo por uma parcela das vítimas pode inibir o criminoso, gerando uma externalidade para toda a sociedade.

No modelo econométrico, buscou-se captar os determinantes do resultado do Referendo nos municípios. As principais variáveis explicativas consideradas foram: taxa de homicídio em 2002 e a sua variação entre 1995 e 2002. Além das estimativas para o nível municipal, utilizou-se como ponderador a proporção de eleitores que compareceram à votação em cada município, com o intuito de captar a importância de cada município no resultado do referendo.

Considerando o modelo ponderado, os resultados sugerem que: i) na maioria dos Estados, quanto maior a taxa de homicídios, menor a proporção de votos no NÃO - um resultado esperado, haja visto que tal variável pode estar correlacionada com o custo da existência do mercado legal de armas; ii) quanto maior a variação da taxa de homicídios, maior a proporção de votos no NÃO - se esta variável capta a percepção do eleitor sobre a escalada recente da violência, isto indica que, possivelmente, o eleitor não está disposto a abrir mão do efeito externalidade e confiar sua segurança somente ao Estado.

\section{Referências Bibliográficas}

Ayres, I. \& Donohue III, J. J. (2003). Shooting down the "more gun less crime" hypothesis. Stanford Law Review, 55.

\footnotetext{
${ }^{23}$ Os custos sociais são maiores, por exemplo, porque a busca e captura de um criminoso é maior em uma grande cidade do que em uma pequena.

${ }^{24}$ Em Referendo (2005), argumenta-se que alguns fazendeiros defendiam o SIM por acreditarem que a proibição geraria uma queda no potencial de violência dos invasores de terras. É possível que este resultado corrobore esta hipótese, mesmo que os defensores do NÃO pensassem diferentemente.
} 
Buchanan, J. M. \& Tullock, G. (1962). The Calculus of Consent: Logical Foundations of Constitutional Democracy. University of Michigan Press.

De La Merced, M. (2002). Bellesiles resigns as fraud investigation ends. The Emory Wheel Online. http://www . emorywheel. com/vnews/display.v/ART/2002/10/25/3db9bc0a08df2.

Donohue, J. J. \& Levitt, S. D. (2001). The impact of legalized abortion on crime. The Quarterly Journal of Economics, 116(2):379-420. http://ideas.repec.org/a/tpr/qjecon/ v116y2001i2p379-420.html.

Helland, E. \& Tabarrok, A. (2004). Using placebo laws to test "more guns, less crime". Advances in Economic Analysis \& Policy, 4(1).

Kovandzic, T. V. \& Marvell, T. B. (2002). Right-to-carry concealed handguns and violent crime: crime control through gun decontrol? http://papers.ssrn.com/sol3/papers.cfm?abstract $\backslash$ _id= 321820 .

Kwon, I. G. \& Baack, D. W. (2005). The effectiveness of legislation controlling gun usage: a holistic measure of gun control legislation. American Journal of Economics and Sociology, 64:533-547.

Lott, J. R. (1999). More guns, less crime: A response to ayres and donohue. Yale Law \& Economics Research Paper, 247.

Lott, J. R. (2004). Right-to-carry laws and violent crime revisited: Clustering, measurement error, and state-by-state break downs. http: //ssrn . com/abstract $=523002$.

Lott, J. R. \& Landes, W. M. (2000). Multiple victim public shootings. http://ssrn. com/abstract= 272929.

Lott, J. R., Plassmann, F., \& Whitley, J. E. (2002). Confirming more guns, less crime. http://ssrn . com/ abstract $=372361$.

Matsusaka, J. G. (1992). Economics of direct legislation. The Quarterly Journal of Economics, 107(2):54171. http://ideas.repec.org/a/tpr/qjecon/v107y1992i2p541-71.html.

Matsusaka, J. G. (2005a). Direct democracy works. Journal of Economic Perspectives, 19(2):185-206.

Matsusaka, J. G. (2005b). The eclipse of legislatures: Direct democracy in the 21st century. Public Choice, 124(1-2).

Noah, T. (2003). The bellesiles of the right? another firearm scholar whose dog ate his data. Slate. http://slate.msn.com/id/2078084/.

Plassmann, F. \& Lott, J. R. (2002). More readers of gun magazines, but not more crimes. http: //ssrn . com/abstract $=320107$.

PNUD (2003). Atlas do desenvolvimento humano.

Rabin, M. (1998). Psychology and economics. Journal of Economics Literature, XXXVI:11-46.

Referendo (2005). Sobre a proibição da comercialização de armas de fogo e munições. Wikipedia. http://pt.wikipedia.org/wiki/Referendo_Sobre_a_Proibição_do_Comércio_de_ Armas_e_Munição_no_Brasil.

Revista Consultor Jurídico (2005). Posição de tiro - presidentes de seccionais são a favor do desarmamento. http://conjur.estadao.com.br/static/text/38221, 1. 
TSE (2005). Tribunal Superior Eleitoral - dados sobre eleições. http: //www . tse .gov . br.

White, H. (1980). A heteroscedasticity-consistent covariance matrix estimator and a direct test for heteroscedasticity. Econometrica, 48.

Wittman, D. A. (1999). O mito do fracasso da democracia - por que as instituições políticas são eficientes. Bertrand Brasil. 


\section{A. TABELAS}

Tabela 3 - Estatísticas Descritivas - Representatividade da Amostra Utilizada

\begin{tabular}{|c|c|c|c|c|c|c|}
\hline \multicolumn{7}{|c|}{ Variável dependente: Proporção de votos NÃO } \\
\hline Unidade da Federação & Amostra & $\mathrm{N}^{0}$ de Observações & Média & $\begin{array}{l}\text { Desv. } \\
\text { Padrão }\end{array}$ & Mínimo & Máximo \\
\hline \multirow{2}{*}{ RO } & Completa & 52 & 81,50 & 4,45 & 70,78 & 90,27 \\
\hline & Analisada & 24 & 81,19 & 4,56 & 73,84 & 90,27 \\
\hline \multirow{2}{*}{$\mathrm{AC}$} & Completa & 22 & 90,34 & 4,40 & 78,8 & 97,44 \\
\hline & Analisada & 9 & 89,57 & 5,00 & 78,8 & 96,93 \\
\hline \multirow{2}{*}{$\mathrm{AM}$} & Completa & 62 & 81,94 & 7,80 & 51,98 & 95,15 \\
\hline & Analisada & 20 & 82,02 & 5,57 & 73,68 & 91,47 \\
\hline \multirow{2}{*}{$\mathrm{RR}$} & Completa & 15 & 91,06 & 3,09 & 81,90 & 83,55 \\
\hline & Analisada & 5 & 90,07 & 1,82 & 88,37 & 92,77 \\
\hline \multirow[b]{2}{*}{ PA } & Completa & 143 & 74,52 & 11,01 & 41,24 & 94,55 \\
\hline & Analisada & 55 & 73,84 & 11,49 & 41,24 & 90,89 \\
\hline \multirow[b]{2}{*}{$\mathrm{AP}$} & Completa & 16 & 84,03 & 7,21 & 69,89 & 93,01 \\
\hline & Analisada & 4 & 84,44 & 5,73 & 76,08 & 88,39 \\
\hline \multirow{2}{*}{ TO } & Completa & 139 & 81,66 & 5,64 & 63,02 & 93,29 \\
\hline & Analisada & 20 & 82,57 & 6,18 & 67,04 & 90,64 \\
\hline \multirow{2}{*}{ MA } & Completa & 217 & 64,53 & 12,57 & 26,71 & 89,01 \\
\hline & Analisada & 33 & 68,42 & 11,15 & 38,92 & 89,01 \\
\hline \multirow[b]{2}{*}{ PI } & Completa & 223 & 66,88 & 9,84 & 37,29 & 88,04 \\
\hline & Analisada & 12 & 62,95 & 8,69 & 47,30 & 79,26 \\
\hline \multirow[b]{2}{*}{$\mathrm{CE}$} & Completa & 184 & 55,19 & 10,08 & 26,47 & 76,64 \\
\hline & Analisada & 86 & 54,93 & 9,59 & 31,60 & 76,64 \\
\hline \multirow{2}{*}{$\mathrm{RN}$} & Completa & 167 & 64,86 & 6,99 & 48,08 & 81,21 \\
\hline & Analisada & 30 & 64,37 & 8,65 & 49,78 & 80,21 \\
\hline \multirow{2}{*}{ PB } & Completa & 223 & 64,07 & 8,56 & 42,12 & 83,73 \\
\hline & Analisada & 40 & 63,81 & 8,45 & 49,56 & 83,73 \\
\hline \multirow{2}{*}{$\mathrm{PE}$} & Completa & 185 & 57,62 & 7,99 & 40,20 & 78,24 \\
\hline & Analisada & 137 & 57,17 & 7,57 & 40,20 & 74,57 \\
\hline \multirow{2}{*}{$\mathrm{AL}$} & Completa & 102 & 56,78 & 7,70 & 27,28 & 75,45 \\
\hline & Analisada & 67 & 56,21 & 7,92 & 27,28 & 70,15 \\
\hline \multirow{2}{*}{ SE } & Completa & 75 & 65,77 & 6,84 & 47,08 & 81,10 \\
\hline & Analisada & 35 & 66,91 & 7,21 & 50,46 & 81,10 \\
\hline \multirow{2}{*}{ BA } & Completa & 417 & 55,34 & 9,41 & 21,40 & 84,58 \\
\hline & Analisada & 127 & 54,85 & 10,87 & 27,67 & 84,58 \\
\hline \multirow{2}{*}{ MG } & Completa & 853 & 61,48 & 8,22 & 32,17 & 81,79 \\
\hline & Analisada & 150 & 61,31 & 7,89 & 37,64 & 81,79 \\
\hline & Completa & 78 & 58,34 & 7,72 & 37,42 & 75,32 \\
\hline ES & Analisada & 52 & 58,45 & 7,25 & 45,56 & 74,23 \\
\hline & Completa & 92 & 61,61 & 4,74 & 48,90 & 70,89 \\
\hline RJ & Analisada & 59 & 61,88 & 4,77 & 48,90 & 70,89 \\
\hline & Completa & 645 & 64,43 & 5,22 & 48,34 & 80,91 \\
\hline SP & Analisada & 263 & 64,35 & 5,00 & 50,65 & 76,02 \\
\hline & Completa & 399 & 74,25 & 7,55 & 53,40 & 92,77 \\
\hline PR & Analisada & 162 & 74,70 & 7,10 & 60,88 & 90,47 \\
\hline SC & Completa & 293 & 81,80 & 6,65 & 52,60 & 92,75 \\
\hline $\mathrm{SC}$ & Analisada & 77 & 82,09 & 7,01 & 52,60 & 92,75 \\
\hline & Completa & 496 & 89,13 & 3,17 & 77,88 & 96,61 \\
\hline RS & Analisada & 143 & 89,41 & 2,88 & 81,43 & 95,02 \\
\hline & Completa & 78 & 76,84 & 4,68 & 63,17 & 86,21 \\
\hline MS & Analisada & 59 & 77,19 & 4,48 & 68,10 & 86,21 \\
\hline & Completa & 141 & 81,85 & 4,59 & 69,17 & 90,55 \\
\hline MT & Analisada & 81 & 82,04 & 4,07 & 70,53 & 90,52 \\
\hline$G 0$ & Completa & 246 & 72,96 & 5,72 & 54,00 & 84,47 \\
\hline GO & Analisada & 80 & 72,67 & 5,39 & 59,14 & 84,47 \\
\hline $\mathrm{DF}$ & Completa & 1 & 56,83 & . & 56,83 & 56,83 \\
\hline$D F$ & Analisada & 1 & 56,83 & . & 56,83 & 56,83 \\
\hline
\end{tabular}




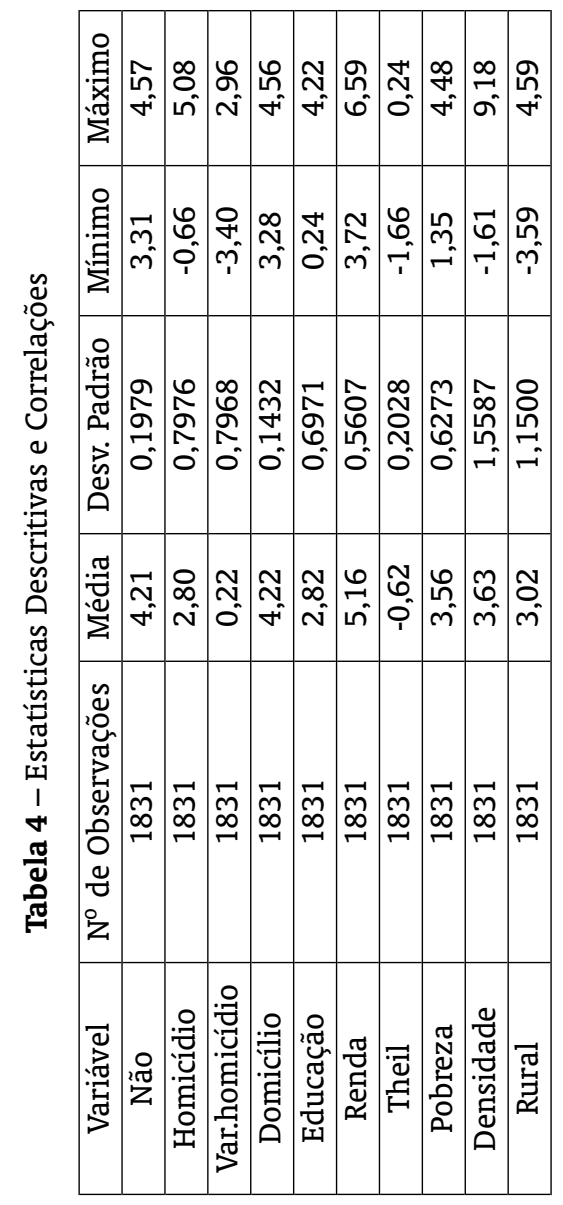

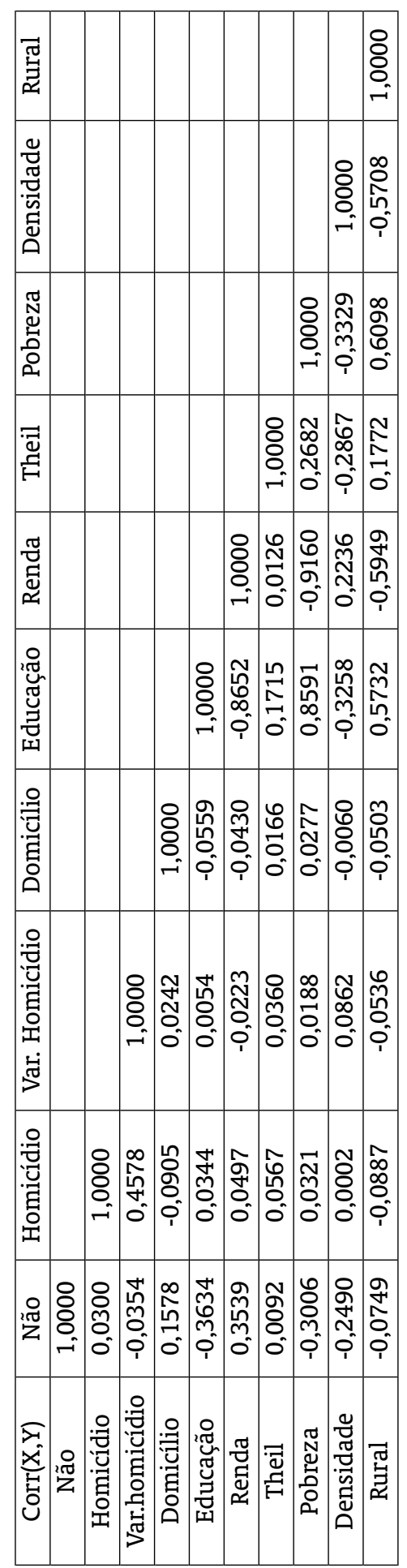




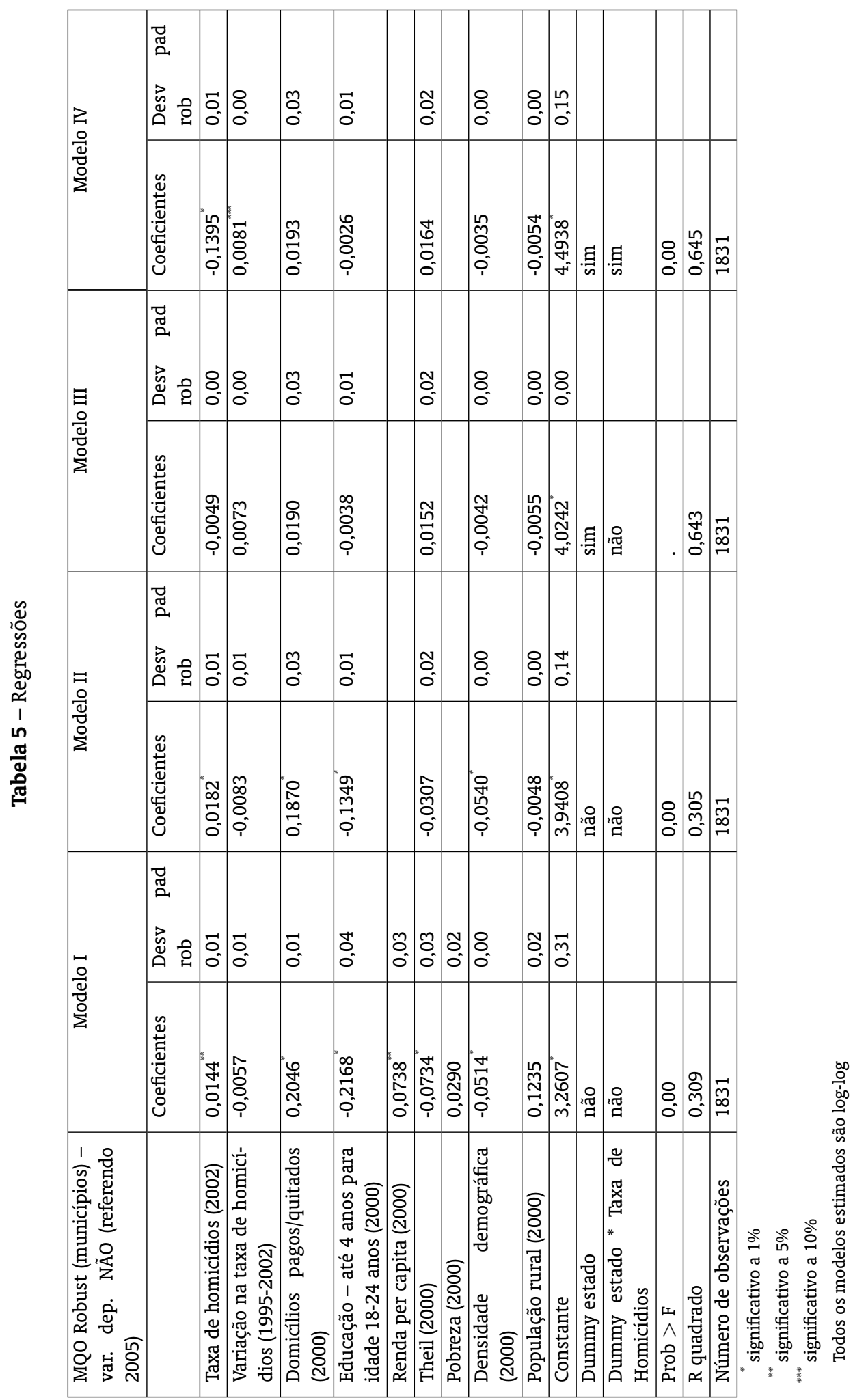




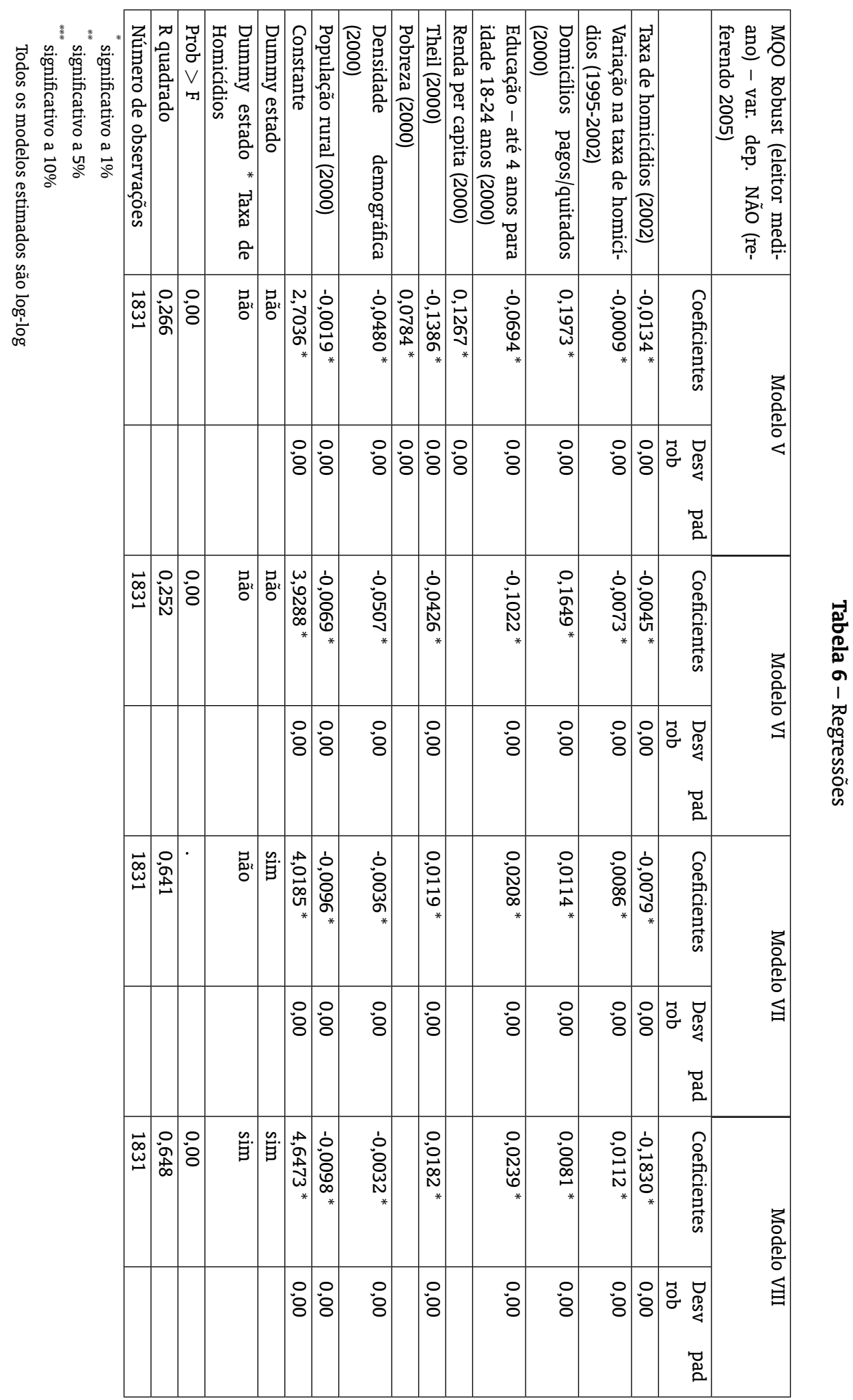


Tabela 7 - Regressão municípios - I

\begin{tabular}{|c|c|c|}
\hline Variável & VIF & 1/VIF \\
\hline Renda & 16,37 & 0,061072 \\
\hline Pobreza & 13,43 & 0,074443 \\
\hline Educação & 5,11 & 0,195886 \\
\hline Rural & 2,33 & 0,429138 \\
\hline Theil & 2,15 & 0,166154 \\
\hline Densidade & 1,71 & 0,583231 \\
\hline Homicídio & 1,43 & 0,701680 \\
\hline Var.Homicídio & 1,33 & 0,751802 \\
\hline Domicílios & 1,07 & 0,931835 \\
\hline Média VIF & 4,99 & \\
\hline
\end{tabular}

Tabela 9 - Regressão eleitor mediano - V

\begin{tabular}{|c|c|c|}
\hline Variável & VIF & 1/VIF \\
\hline Renda & 18,07 & 0,055352 \\
\hline Pobreza & 15,36 & 0,065095 \\
\hline Educação & 5,67 & 0,176246 \\
\hline Rural & 2,52 & 0,397268 \\
\hline Theil & 2,19 & 0,457629 \\
\hline Densidade & 1,79 & 0,558647 \\
\hline Homicídio & 1,40 & 0,715339 \\
\hline Var.Homicídio & 1,33 & 0,754341 \\
\hline Domicílios & 1,12 & 0,888895 \\
\hline Média VIF & 5,49 & \\
\hline
\end{tabular}

Tabela 8 - Regressão municípios - II

\begin{tabular}{|c|c|c|}
\hline Variável & VIF & 1/VIF \\
\hline Rural & 2,03 & 0,492774 \\
\hline Densidade & 1,60 & 0,626920 \\
\hline Educação & 1,52 & 0,658971 \\
\hline Homicídio & 1,32 & 0,758623 \\
\hline Var.Homicídio & 1,29 & 0,774919 \\
\hline Theil & 1,10 & 0,905720 \\
\hline Domicílios & 1,02 & 0,978885 \\
\hline Média VIF & 1,41 & \\
\hline
\end{tabular}

Tabela 10 - Regressão eleitor mediano - VI

\begin{tabular}{|c|c|c|}
\hline Variável & VIF & $1 /$ VIF \\
\hline Rural & 2,25 & 0,443464 \\
\hline Densidade & 1,73 & 0,578431 \\
\hline Educação & 1,67 & 0,598986 \\
\hline Var.Homicídio & 1,25 & 0,797322 \\
\hline Homicídio & 1,25 & 0,800396 \\
\hline Theil & 1,07 & 0,936555 \\
\hline Domicílios & 1,06 & 0,945460 \\
\hline Média VIF & 1,47 & \\
\hline
\end{tabular}

